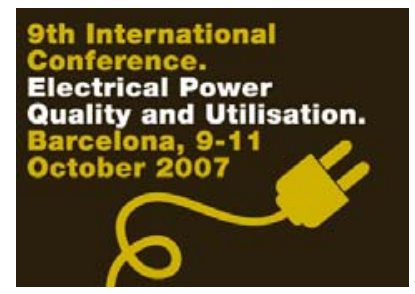

\title{
Characterization of Spectral Density of Wind Farm Power Output
}

\author{
Joaquín Mur-Amada, Ángel A. Bayod-Rújula \\ Zaragoza University, Department of Electrical Engineering \\ C/ María de Luna 3, Ed. Torres Quevedo \\ 50018 - Zaragoza (Spain) \\ phone: +34976 761920, e-mail: joako@unizar.es and aabayod@unizar.es
}

\begin{abstract}
In this work, the power oscillations during continuous operation of a whole wind farm and a single turbine are characterized for timescales in the range of minutes to fractions of seconds. A stochastic model is derived in time and frequency domains to link the overall behavior of a large number of wind turbines from the operation of a single turbine.

A literature review on experimental data of Power Spectral Densities (PSD) and periodograms (averaged spectrum) of power output from wind turbines and wind farms are presented. The variability of PSD is also studied through spectograms (joint time-frequency domain)
\end{abstract}

Index Terms - wind, flicker, fluctuation, stochastic process.

List of acronyms

DFIG Doubly Fed Induction Generator

DTF Discrete Fourier Transform

PSD Power Spectral Density

RMS Root Mean Squared (value)

SQIG Squirrel Cage Induction Generation

VRIG Variable Resistance Induction Generator

\section{INTRODUCTION}

$\mathrm{O}$ scillations due to momentary wind speed variations and turbine dynamics can be classified as correlated and uncorrelated. Slow fluctuations (in the range of tens of minutes and hours) are mainly due to meteorological dynamics and they are highly correlated between near wind farms.

Fast fluctuations have lower spatial correlation $[1,2,3]$ and wind gust and turbulence effects are smoothed in the output of the wind farm. A swift gust arriving simultaneously to all turbines dispersed in an area of kilometers is also very uncommon [4]. The correlated component of wind is estimated in [5]

This work has been partially supported by Department of Education and Culture of Aragón (B134/1998 grant). from the Davenport type and Schlez and Infield's decay factors [6], showing that coherence for distances greater than 100 $\mathrm{m}$ is bellow $10^{-20}$ at tower shadow frequencies (between $0.5 \mathrm{~Hz}$ and $2 \mathrm{~Hz}$ ). In fact, the coherence for the usual dimension of a wind farm is low for oscillations quicker than $0,001 \mathrm{~Hz}$. Thus, the study presented here is valid for fluctuations inside the usual 10 or 15 minutes intervals (i.e., oscillations that happen quicker).

Correlated fluctuations scales proportional to the number of turbines $N$ whereas linearly uncorrelated fluctuations cancel partially among turbines and they scale up typically in a factor $\sqrt{ } N$, according to the central limit theorem. In [29], a transfer function with gain $N$ at low frequencies $(f<0.03 \mathrm{~Hz})$ and gain $\sqrt{ } N$ at high frequencies $(f>0.09 \mathrm{~Hz})$ estimates wind farm output from the output of a single turbine.

\section{Periodic Fluctuations In THE FREQUENCY DOMAIN}

A. Classification of fluctuation components on power output

The instantaneous output can be expressed in frequency components using phasors:

$$
\begin{aligned}
P_{\text {farm }}(t) & =\int_{0}^{\infty} S_{\text {farm }}(f) \cos \left(2 \pi f t+\varphi_{\text {farm }}(f)\right) d f= \\
& =\operatorname{Re}\left[\int_{0}^{\infty} \vec{S}_{f a r m}(f) e^{j 2 \pi f t} d f\right]
\end{aligned}
$$

where $e$ is the base of the natural logarithm, $j$ is the imaginary unit and Re states for the real part of a complex number.

Fluctuations at the point of common coupling (PCC) of the wind farm can be obtained from power balance equations for the average complex power of the wind farm. For usual wind farm configurations, total active losses at full power are less than $2 \%$ and reactive losses are less than $20 \%$, showing a quadratic behavior with generation level [7]. A small-signal model of power losses due to fluctuations inside the wind 
farm can be derived [8], but since they are expected to be up to $2 \%$ of the fluctuation, the increase of power losses due to oscillations can be neglected in the first instance.

Neglecting the increase of power losses in the grid due to fluctuating generation, the sum of oscillating power from the turbines equals the farm output undulation. Therefore, the complex sum of the frequency components of each turbine $\vec{S}_{\text {turbine } i}(f)$ totals the approximate farm output, $\vec{S}_{\text {farm }}(f)$.

$\vec{S}_{\text {farm }}(f)=S_{\text {farm }}(f) e^{j \varphi_{\text {farm }}(f)} \approx \sum_{i=1}^{N_{\text {turbines }}} S_{\text {turbine } i}(f) e^{j \varphi_{i}(f)}$

\section{B. Parameterization of power output spectrum}

Periodic fluctuations appear as peaks at their frequency in the spectrum, whereas random fluctuations (which have neither a periodic pattern nor a characteristic frequency) can be associated with the tendency of the smoothed spectrum. Since the required frequency resolution is low, the power spectrum has been smoothed in order to lower the PSD variance at the cost of a decrease frequency resolution (the fluctuating power is kept constant).

In Fig. 1 to 4 , the original power spectrum is in grey whereas the estimated PSD is in black (linearly averaged periodogram). Red line is the model (7) (the output of a system of fractional order between 1.1 to 1.6 with a root and a pole excited by white noise). Green line is a measure of the error of the model precision computed as the difference of (8) computed from the model (7) or from actual spectrum integrating from frequency $f$ up to $25 \mathrm{~Hz}$. PSD units are $\mathrm{W}_{\text {rms }}^{2}$ per herz.

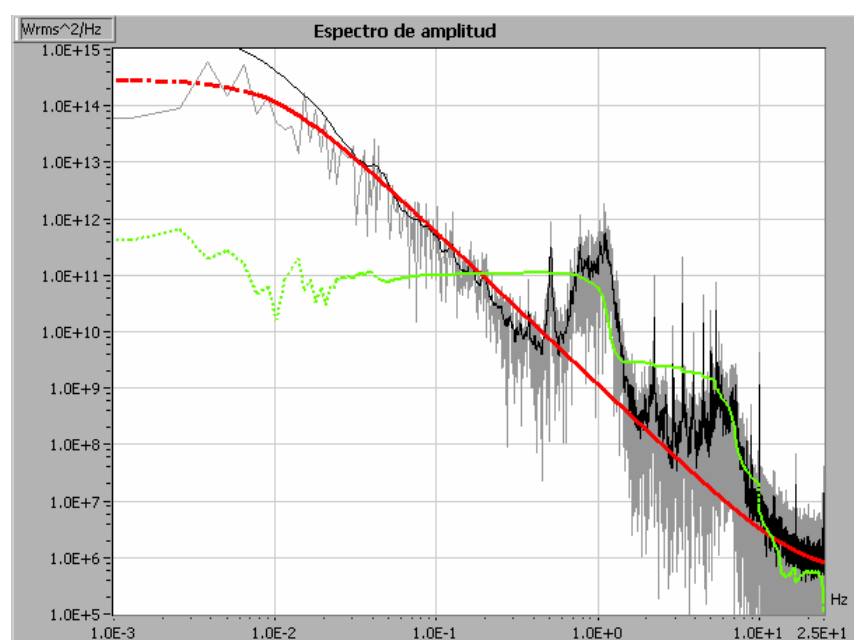

Fig. 1: PSD for a $750 \mathrm{~kW}$ induction generator, stall regulation WT operating at $6,5 \mathrm{~m} / \mathrm{s}$ at Valdeduadros.

There is a noise floor (represented by a solid horizontal line) in turbines with electronic converters, giving evidence that this type of turbines have lower tower shadow modulation but higher fluctuation content at higher frequencies (in the range from 3 to $50 \mathrm{~Hz}$ ) due to control issues, effect of switching devices and higher uncertainty of measuring system. In the measured squirrel cage induction generator, the noise floor is significantly smaller and it can be neglected. The actual spectrum of power from a wind turbine depends on many parameters such as turbine technology and wind regime. Karman and Kaimal wind turbulence spectrum show a fractional relation- ship with frequency at frequencies bellow the integral time [4]. The peak of wind PSD is usually in the order of minutes and the turbine dynamics are negligible there.

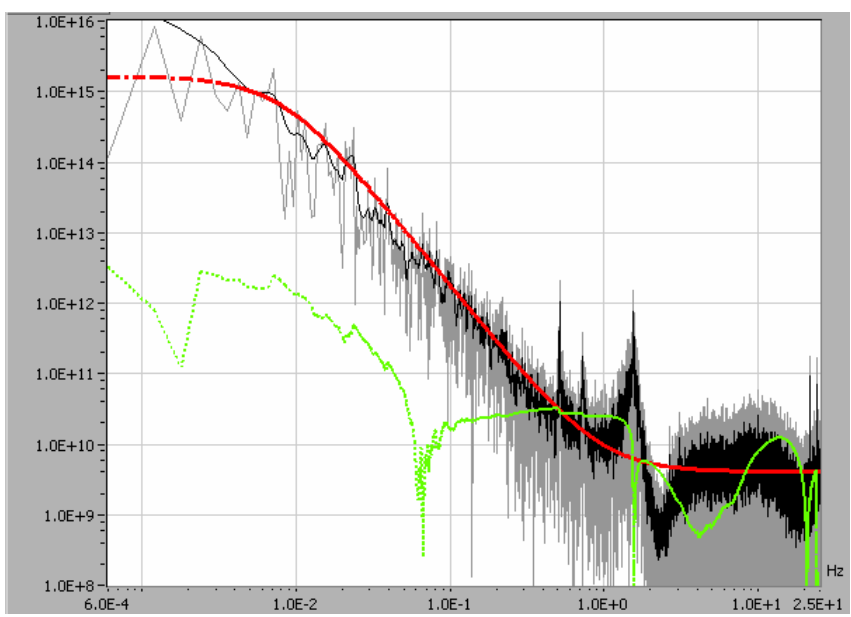

Fig. 2: PSD of Remolinos wind turbine operating at low winds.

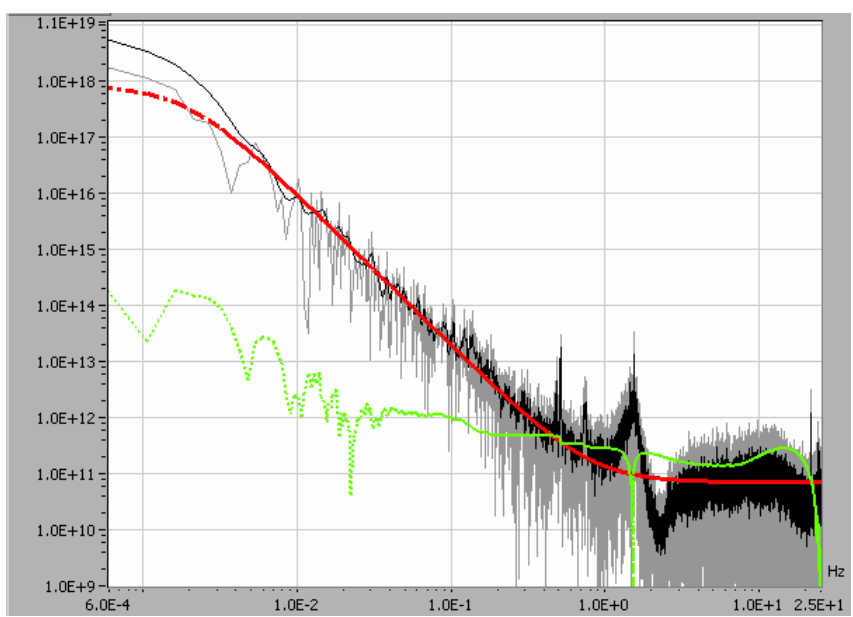

Fig. 3: PSD of Remolinos wind farm operating at low winds.

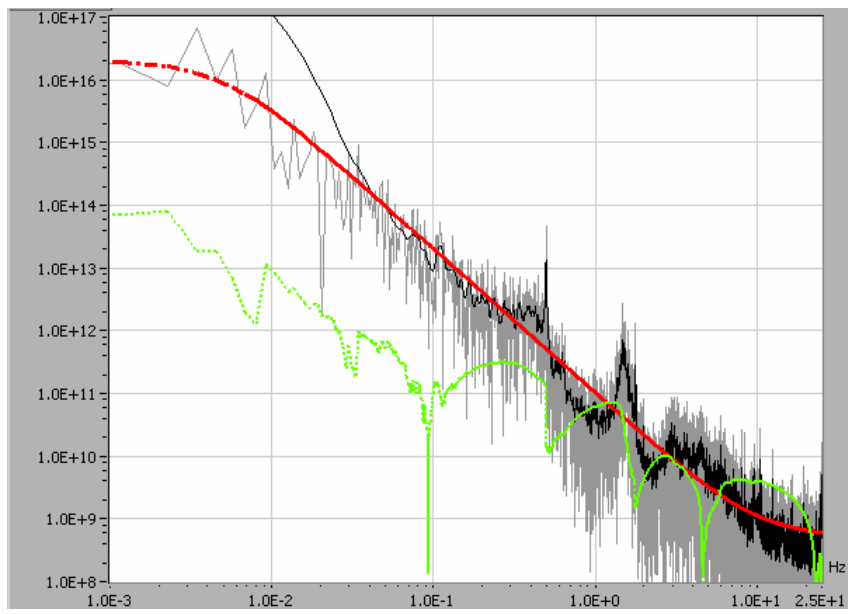

Fig. 4: PSD of Borja farm operating around $6 \mathrm{~m} / \mathrm{s}$.

The PSD of active and reactive power output has several components:

- Output of a system of fractional order $r$ slightly bigger than unity $(1<r<1.5)$ and characteristic time $\tau_{1}$ in the range of milihertzs. 
- In some turbines with electronic power converters, there is a noise floor at high frequencies. Therefore, the spectrum is basically constant from a given frequency $f_{\text {noise floor }}=1 / \tau_{2}$. In other turbines, this effect does not occur and $\tau_{\text {floor }} \approx 0$.

- The deviation of the actual system from the asymptotic spectrum trend can be characterized as an admittance $G(f)$ which models the cyclic components of the spectrum. The admittance $G(f)$ is significantly different from unity at harmonics of rotor frequency $f_{\text {rotor }}=p$.

o $G(f)$ is below unity at frequencies $f$ where the system is damped respect to the fractional system.

o $G(f)$ is significantly above unity at frequencies $f$ where the system presents a periodic pattern (for example, at blade frequency $\left.f_{\text {blade }}=3 f_{\text {rotor }}=3 p\right)$.

- The delta impulse at origin due to the mean value of power, $\langle P(t)\rangle$.

A simple model (3) with a structure similar to will be used to characterize power fluctuations in partial load generation in the range from milihertzs to $35 \mathrm{~Hz}$ from the grid point of view. It will be used also to compare spectrum main characteristic of spectra available in the literature.

$$
\left|S^{2}(f)\right|=H(f) G(f)
$$

where

$$
H(f)=\langle P(t)\rangle^{2} \delta_{0}(f)+K\left(\frac{1+\left(\tau_{2} f\right)^{2}}{1+\left(\tau_{1} f\right)^{2}}\right)^{r}
$$

and $\delta$ is the delta of Dirac function to model the mean value of power,.

The time constant $\tau_{1}$ is in the range of minutes and $H(f)$ can have a simpler expression for $f>1 / \tau_{1} \sim m H z$.

$$
H(f) \underset{f \gg 1 / \tau_{1}}{\approx} K_{1}\left(\tau_{2}^{2}+\frac{1}{f^{2}}\right)^{r}
$$

where $r$ is the order of the system and it can be computed as the slope of $|S(f)|$ in a double logarithmic plot. In most turbines the spectrum decreases continuously and thus $\tau_{2} \approx 0$. In some turbines, $|S(f)|^{2}$ remains approximately constant at the noise floor $K_{1} \tau_{2}{ }^{2 r}$ in frequencies between $f_{\text {noise floor }}$ $=1 / \tau_{2}$ and $35 \mathrm{~Hz}$.

Exact frequency of fluctuations can be very important for avoiding mechanical resonance modes in the design of a wind turbine, but they play a secondary role in the grid. The main power quality due to power fluctuations is flicker, and weighting filter on flickermeter varies smoothly with frequency. Moreover, the PSD shows some wide peaks at blade frequency indicating that the amplitude and phase of tower shadow effect shows a modulation of tower shadow and has a somewhat variable frequency in variable speed turbines. Therefore, a simplified admittance function $G(f)$ in $(6)$ with a few harmonics of rotor frequency $f_{\text {rotor }}=p$ can have enough precision in many cases.

$$
G(f)=1+\sum_{k} g_{k p}^{2} \delta_{k p}(f) \approx 1+g_{p}^{2} \delta_{p}(f)+g_{3 p}^{2} \delta_{3 p}(f)+\ldots
$$

where $\delta$ is the delta of Dirac function, which concentrates power in the frequency band of interest (around rotor frequency and its).
At full load generation, wind fluctuations of frequencies bellow $0,1 \mathrm{~Hz}$ are strongly attenuated in electrical power output (at such frequencies, the turbine dynamics can be neglected and the power curve is flat or almost flat). $G(f)$ can be used to characterize behavior of slow fluctuations for full generation, (from some seconds up to an hour).

$$
G(f)=K_{2}\left(\frac{f^{2}}{1+\left(\tau_{3} f\right)^{2}}\right)^{m}+\delta_{0}(f)+\sum_{k} g_{k p}{ }^{2} \delta_{k p}(f)
$$

The variance of instantaneous power measured during a time interval $\mathrm{T}$ can be computed from (5) and (6):

${\sigma_{P}}^{2}=\int_{1 / T}^{35 H z} S^{2}(f) d f \approx K_{1} \frac{T^{2 r-1}}{2 r-1}+\sum_{k} g_{k p}{ }^{2}\left|S^{2}(k p)\right|$

Frequently, the variance is computed not from instantaneous power but from mean averages integrated during a short period $T_{\log }$ (for example, $T_{\log }=1 \mathrm{~s}$ or $T_{\log }=1 / 4 \mathrm{~S}$ ). The process of logging mean values measured during a short period $T_{\log }$ can be modeled with the transfer function $F(s)$.

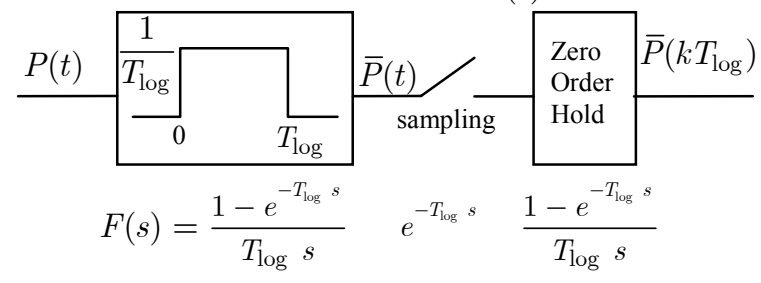

Fig. 5: Model of the wattmeter of the wind farm

The attenuation of frequencies due to the use of discretized logged data instead of continuous variable is:

$$
|F(f)|=\left(\frac{\sin \left(\pi f T_{\log }\right)}{\pi f T_{\log }}\right)^{2}
$$

The variance of power computed during a time interval $\mathrm{T}$ from data recorded each $T_{\log }$ seconds is:

$$
\begin{aligned}
\sigma_{P}^{2} & =\int_{1 / T}^{35 H z} S^{2}(f)|F(f)|^{2} d f \approx \int_{1 / T}^{0,2 / T_{\log }} S^{2}(f) d f \approx \\
& \approx K_{1} \frac{T^{2 r-1}-\left(T_{\log } / 0,2\right)^{2 r-1}}{2 r-1} \underset{T \gg T_{\log }}{\text { Usually }} K_{1} \frac{T^{2 r-1}}{2 r-1}
\end{aligned}
$$

Table II shows the adjusted parameters of (3) from measures taken by the author or estimated from the bibliography. Unfortunately, there is not enough information in the references to estimate $K_{1}$ or the interval variance of power ${\sigma_{P}}^{2}$.

\section{Sum of correlated and uncorrelated spectral components}

The mean fluctuation of the farm $\left\langle\left|\vec{S}_{f a r m}(f)\right|\right\rangle$ can be estimated from mean turbine fluctuation $\left\langle\left|\vec{S}_{\text {turbine }} i(f)\right|\right\rangle$ by its average coherence $|J(f)|$ [29].

$$
\begin{gathered}
\left\langle\left|\vec{S}_{\text {farm }}(f)\right|\right\rangle=|J(f)|\left\langle\left|\vec{S}_{\text {turbine } i}(f)\right|\right\rangle \\
\sqrt{N} \lesssim|J(f)| \lesssim N
\end{gathered}
$$

If the spectrum of a single turbine $i,\left|\vec{S}_{\text {turbine } i}(f)\right|$, and the spectrum of the farm $\left|\vec{S}_{\text {farm }}(f)\right|$ is available, the components $\left|\vec{S}_{\text {farm, correlated }}(f)\right|$ and $\left|\vec{S}_{\text {farm, uncorrelated }}(f)\right|$ can be estimated provided the behavior in all turbines is similar.

An analogous procedure can be derived to sum fluctuations of wind farms of a geographical area. Recall that if hourly or 
slower fluctuations are studied, meteorological dynamics are dominant and other approaches are more suitable.

\section{Sum of Phasors}

Any random sinusoidal signal can be considered as a random phasor, i.e., a vector with random length and angle. So, irrespective of the type of application [9, 10], we encounter the following general mathematical problem. There are vectors with lengths $S_{i \text {, uncorr }}$ and angles $\varphi_{i}=\operatorname{Arg}\left(\vec{S}_{i, \text { uncorr }}\right)$ where $S_{i, \text { uncorr }}$ and $\varphi_{i}$, are random variables. It is desired to obtain the probability density function (pdf) of the length of the resulting vector. A comprehensive literature survey on the sum of random vectors can be obtained from [11].

\section{E. Interpreting distributions of the sum of fluctuations}

Fluctuation amplitude mean value or the root squared sum (RMS) of the fluctuation can be computed from the parameters of distributions of Table I.

For example, average fluctuation of a wind farm of $N$ turbines can be easily computed since the mean of a Rayleigh distribution of scale parameter $\sigma$ is $\mu_{\text {Rayleigh }(\sigma)}=\sigma \sqrt{\pi / 2}$. The amplitude of fluctuation of a wind farm at frequency $f$ is $\mid \vec{S}_{N}(f)$, a Rayleigh random variable of scale parameter $\sigma_{N}=\sqrt{N / 2}\left|\vec{S}_{1}(f)\right|$, where $\left|\vec{S}_{1}(f)\right|$ is the amplitude of fluctuation at a single turbine. The mean amplitude is:

$$
\left\langle\left|\vec{S}_{N}(f)\right|\right\rangle_{\text {Rayleigh }\left(\sigma_{N}(f)\right)} \sqrt{N \pi / 4}\left|\vec{S}_{1}(f)\right| \approx 0.886 \sqrt{N}\left|\vec{S}_{1}(f)\right|
$$

TABLE I: SUMMARY OF STATISTICAL PROPERTIES OF WIND FARM UNCORRELATED SINUSOIDAL FLUCTUATIONS

\begin{tabular}{|c|c|c|}
\hline $\begin{array}{c}\text { Turbine } \\
\text { fluctuation } \\
\text { distribution }\end{array}$ & $\begin{array}{c}\left|\vec{S}_{1}(f)\right| \text { is deterministic. } \\
\text { Phasor } \vec{S}_{1}(f) \text { of fixed modulus and random angle. }\end{array}$ & $\vec{S}_{1}(f)$ is a complex Gaussian random variable. \\
\hline $\begin{array}{l}1 \text { turbine } \\
\text { in the wind } \\
\text { farm }\end{array}$ & $\begin{array}{l}\text { Phasor } \vec{S}_{1}(f) \text { of fixed modulus and random angle. } \\
P D F\left(S_{1}(f)\right)=\delta\left(\left|\vec{S}_{1}(f)\right|-S_{1}(f)\right) ; \\
\sigma_{1}(f)=\left|\vec{S}_{1}(f)\right| / \sqrt{2}=\text { standard deviation of the projection of } \\
\text { the phasor } \vec{S}_{1}(f) \text { in the real axis, } \\
\sqrt{\left\langle S_{1 . f}^{2}(t)\right\rangle}=\text { mean RMS value of the instantaneous fluctuation } \\
\text { at frequency } f \text { at a single turbine }=\sigma_{1}(f) \\
P D F\left(S_{1, f}^{2}(t)\right)=\frac{1}{\pi \sqrt{\left|\vec{S}_{1}(f)\right|^{2}-S_{1, f}^{2}(t)}} \\
\delta(\cdot) \text { is the Dirac Delta }\end{array}$ & $\begin{array}{l}\vec{S}_{1}(f) \text { is a complex Gaussian random variable with } \\
\text { zero mean and standard deviation } \sigma_{1}(f) \\
\vec{S}_{1}(f) \sim \mathbb{C} N\left(0, \sigma_{1}(f)\right) \\
S_{1, f}(t) \sim N\left(0, \sigma_{1}(f)\right) \\
\left|\vec{S}_{1}(f)\right| \sim \text { Rayleigh }\left(\sigma_{1}(f)\right) \\
\operatorname{PDF}\left(\left|\vec{S}_{1}(f)\right|\right)=\frac{1}{\sqrt{2 \pi} \sigma_{1}(f)} \exp \left[-\frac{1}{2}\left|\frac{\vec{S}_{1}(f)}{\sigma_{1}(f)}\right|^{2}\right]\end{array}$ \\
\hline $\begin{array}{l}2 \text { turbine } \\
\text { in the wind } \\
\text { farm }\end{array}$ & $\begin{array}{c}\operatorname{PDF}\left(S_{2}(f)\right)=\frac{1}{\pi \sqrt{2\left|\vec{S}_{1}(f)\right|^{2}-S_{2}^{2}(f)}} \\
\sigma_{2}(f)=\left|\vec{S}_{1}(f)\right|=\sqrt{2} \sigma_{1}(f) \\
\operatorname{PDF}\left(S_{2, f}(t)\right)=\frac{-2 \sigma_{2}(f)}{\pi^{2}\left|S_{2, f}(t)\right|} \operatorname{Im}\left[\operatorname{EllipticK}\left(\frac{2 \sigma_{2}(f)}{\left(S_{2, f}(t)\right)^{2}}\right)\right]\end{array}$ & $\begin{array}{l}\vec{S}_{2}(f) \text { is a complex Gaussian random variable } \\
\text { with zero mean and standard deviation } \sigma_{2}(f) \\
\qquad \sigma_{2}(f)=\sqrt{2} \sigma_{1}(f) \\
\vec{S}_{2}(f) \sim \mathbb{C} N\left(0, \sqrt{2} \sigma_{1}(f)\right) \\
S_{2, f}(t) \sim N\left(0, \sqrt{2} \sigma_{1}(f)\right) \\
S_{2}(f) \sim \text { Rayleigh }\left(0, \sqrt{2} \sigma_{1}(f)\right)\end{array}$ \\
\hline \multirow[b]{2}{*}{$\begin{array}{l}\mathrm{N} \text { turbines } \\
\text { in the wind } \\
\text { farm } \\
(\mathrm{N}>4)\end{array}$} & $\begin{array}{l}\quad P D F_{N}\left(S_{N}(f)\right) \simeq \frac{S_{N}}{\left(\sqrt{N / 2} S_{1}\right)^{2}} \exp \left[-\frac{1}{2}\left(\frac{S_{N}}{\sqrt{N / 2} S_{1}}\right)^{2}\right] \\
\Rightarrow S_{N}(f) \text { has (very approximately) a Rayleigh distribution } \\
\text { with scale parameter } \sigma_{N}(f)=\sqrt{N / 2}\left|\vec{S}_{1}(f)\right|=\sqrt{N} \sigma_{1}(f)\end{array}$ & $\begin{array}{l}\vec{S}_{N}(f) \text { is a complex Gaussian random variable } \\
\text { with zero mean and standard deviation } \sigma_{N}(f) \\
\qquad \sigma_{N}(f)=\sqrt{N} \sigma_{1}(f) \\
\vec{S}_{N}(f) \sim \mathbb{C} N\left(0, \sqrt{N} \sigma_{1}(f)\right) \\
S_{N}(f) \sim \text { Rayleigh }\left(\sqrt{N} \sigma_{1}(f)\right)\end{array}$ \\
\hline & $\begin{array}{r}\text { The instantaneous uncorrelated fluctuation } \\
S_{N, f}(t)=\operatorname{Re}\left[\vec{S}_{N}(f) e^{-j 2 \pi f t}|=| \vec{S}_{N}\right. \\
\vec{S}_{N}(f) \text { is a complex Gaussian random variable with zero me } \\
\vec{S}_{N}(f) \sim \mathbb{C} N(0, \sqrt{\Lambda} \\
\left|\vec{S}_{N}(f)\right|=\text { uncorrelated fluctuation amplitude, } S_{N}(f) \text {, has a Ray } \\
\left|\vec{S}_{N}(f)\right| \sim \text { Rayleigh }\left(\sigma_{N}(f)\right) \rightarrow \text { mean fluctuation am } \\
\left|\vec{S}_{N}(f)\right|^{2}=\text { sum of squared real and imaginary instantaneous flu } \\
\frac{1}{2}\left\langle\left|\vec{S}_{N}(f)\right|^{2}\right\rangle=\left\langle S_{1, f}^{2}(t)\right\rangle=\text { mean squared value of the }\end{array}$ & $\begin{array}{l}\text { component of frequency } w \text { is: } \\
\text { ) } \operatorname{Cos}\left(2 \pi f t+\varphi_{N}(f)\right) \\
\text { n and standard deviation } \sigma_{N}(f)=\sqrt{N} \sigma_{1}(f), \\
\left.\sigma_{1}(f)\right) \\
\text { eigh distribution with scale parameter } \sqrt{N} \sigma_{1}(f), \\
\text { olitude } \sigma_{N}(f) \sqrt{\pi / 2}=0,886 \sqrt{N} \sigma_{1}(f) \\
\text { ctuation components } \sim \text { Gamma }\left(1,2 N \sigma_{1}^{2}(f)\right) \\
\text { instantaneous fluctuation at frequency } f\end{array}$ \\
\hline
\end{tabular}


TABLE II: COMPARISON OF PARAMETERS OF POWER OUTPUT PSD

\begin{tabular}{|c|c|c|c|c|}
\hline Source & $r$ & $\begin{array}{c}K_{1} \\
\left(\mathrm{~kW}^{2} / \mathrm{Hz}\right)\end{array}$ & $\tau_{2}(\mathrm{~s})$ & Remarks \\
\hline [12], NM-750 kW, SQIG & 1,35 & $1.410^{3}$ & 0 & Fixed speed, stall regulated turbine at Valdecuadros, \\
\hline [12], Gamesa DFIG $640 \mathrm{~kW}$ & 1,23 & $610^{3}$ & 0,5 & Variable speed, pitch wind turbine at Remolinos, $K_{1}$ high \\
\hline $\begin{array}{l}\text { [12], } 17 \text { x } 640 \mathrm{~kW} \text { wind farm, Gamesa } \\
\text { pitch contr. DFIG }\end{array}$ & 1,23 & $10^{5}$ & 0,5 & $\begin{array}{l}\text { Remolinos wind farm with variable speed, pitch con- } \\
\text { trolled wind turbines, } K_{1} \text { high. }\end{array}$ \\
\hline $\begin{array}{c}\text { [12], } 27 \times 600 \mathrm{~kW} \text { turbines, } \\
\text { Vestas pitch controlled VRIG } \\
\end{array}$ & 1,1 & $10^{5}$ & 0 & $\begin{array}{l}\text { Borja wind farm, pitch control and almost fixed speed } \\
\text { (opti-slip control), } K_{1} \text { high. }\end{array}$ \\
\hline $\begin{array}{c}\text { [13], } 5 \text { x 500kW stall-regulated offshore } \\
\text { wind farm }\end{array}$ & $\sim 1,9$ & & 0 & $\begin{array}{c}\text { Bockstigen stall-regulated offshore wind park with vari- } \\
\text { able speed turbines at low winds }\end{array}$ \\
\hline$[13], 5 \times 500 \mathrm{~kW}$ offshore & $\sim 1,6$ & & 0.2 & Constant speed operation at medium or high winds \\
\hline $\begin{array}{c}{[14], 2,5 \mathrm{MW} \text { wind farm }} \\
\text { operating at } 500 \mathrm{~kW} \text {, fixed speed }\end{array}$ & 0.63 & & 0 & $\begin{array}{l}\text { Fixed speed operation. } \\
\text { Noticeable tower shadow pulsation. }\end{array}$ \\
\hline $\begin{array}{c}{[14], 2,5 \mathrm{MW} \text { wind farm }} \\
\text { operating at } 500 \mathrm{~kW} \text {, variable speed }\end{array}$ & 1.3 & & 0.8 & $\begin{array}{l}\text { Good agreement also for } \mathrm{r} \sim 1 \text { and } \tau_{2}=0 \text {. Anti-flicker al- } \\
\text { gorithm avoids tower shadow pulsation }\end{array}$ \\
\hline$[15] 2 \times 225 \mathrm{~kW}$ wind farm & 1,03 & & & Two $225 \mathrm{~kW}$ pitch-controlled turbines. \\
\hline [16], 4 x $180 \mathrm{~kW}$ Alsvik wind farm & $1 *$ & & 0.24 & $\mathrm{~V}_{\text {wind }} \approx 14 \mathrm{~m} / \mathrm{s}$, low turbulence wind at Gotland \\
\hline$[16], 4 \times 180 \mathrm{~kW}$ Alsvik wind farm & $1,1^{*}$ & & 0.24 & $\mathrm{v}_{\text {wind }} \approx 14 \mathrm{~m} / \mathrm{s}$, wake operation \\
\hline [16], 4 x $180 \mathrm{~kW}$ Alsvik wind & 1,15 & & 0.24 & $\mathrm{v}_{\text {wind }} \approx 10 \mathrm{~m} / \mathrm{s}$, low turbulence wind \\
\hline$[17], 10 \times 500 \mathrm{~kW}$ wind farm & 1 & & 0 & Spectrum of active power, fixed-speed, stall-regulated \\
\hline$[17], 10 \times 500 \mathrm{~kW}$ wind farm & 0.86 & & 0 & Spectrum of reactive power, fixed-speed, stall-regulated \\
\hline $\begin{array}{l}{[18] 7 \times 1.5 \mathrm{MW} \text { ENRONWIND EW }} \\
\text { offshore wind farm at Utgrunden }\end{array}$ & $\begin{array}{c}0.7 \sim \\
1.4 \\
\end{array}$ & & $\begin{array}{l}10- \\
20 \\
\end{array}$ & $\begin{array}{l}\text { At full power, almost constant PSD from } 0,05 \mathrm{~Hz} \text { (at me- } \\
\text { dium and low power, constant PSD from } 0,1 \mathrm{~Hz} \text { ) }\end{array}$ \\
\hline $\begin{array}{l}{[19] 7 \text { x } 1.5 \text { MW ENRONWIND EW off- }} \\
\text { shore wind farm at Utgrunden }\end{array}$ & $\sim 1.5$ & & & $\begin{array}{l}\text { Active and reactive power shows an almost linear rela- } \\
\text { tionship up to } 17 \mathrm{~Hz}: \Delta Q \sim \Delta P / 10\end{array}$ \\
\hline [20], MADE AE46/I, $660 \mathrm{~kW}$ & 1 & & 0 & Stall regulated turbine, fixed speed, SQIG \\
\hline [21] 4 x 180 kW, Fig. 5.2 a) & $\sim 1$ & & 0 & Spectrum of active power. Generator fluctuations near $10 \mathrm{~Hz}$. \\
\hline$[21], 4$ x 180 kW ,Fig. 5.2 b) & $\sim 0,8$ & & 0 & Stall regulated turbine, spectrum of reactive power at Alsvik. \\
\hline$[2], 180 \mathrm{~kW}$, constant speed, soft shaft & 1.1 & & 0 & Soft shaft damps high frequency oscillations down \\
\hline$[2], 180 \mathrm{~kW}$, constant speed, stiff shaft & 1.1 & & 3 & Stiff shaft increases oscillations faster that $1 \mathrm{~Hz}$ \\
\hline $\begin{array}{c}{[22],[23] \text { or }[24], 2 \mathrm{MW}, \mathrm{NM} 2000 / 72} \\
\text { turbine at } 9 \mathrm{~m} / \mathrm{s}\end{array}$ & $\begin{array}{c}1,04 \sim \\
1,17\end{array}$ & $\sim 158$ & 0 & Medium power operation $(8 \sim 9 \mathrm{~m} / \mathrm{s})$ \\
\hline $\begin{array}{c}\text { [22], [23] or [24], } 2 \mathrm{MW}, \mathrm{NM} 2000 / 72 \\
\text { turbine at rated wind speed }\end{array}$ & $\begin{array}{c}1,04 \sim \\
1,1\end{array}$ & $\sim 16$ & 0 & Rated power operation $(14 \sim 15 \mathrm{~m} / \mathrm{s})$ \\
\hline$[5], 500 \mathrm{~kW}$ stall regulated turbine & $\sim 1,5$ & $\sim 20$ & 0 & Constant speed, stall regulated wind turbine \\
\hline $\begin{array}{l}\text { [25] multi-megawatt turbine, coordinated } \\
\text { pitch controller }\end{array}$ & $\sim 0.7$ & $\sim 500$ & 0 & Simulation results without reference to real measurements \\
\hline $\begin{array}{l}\text { [25] multi-megawatt turbine, traditional } \\
\text { controller }\end{array}$ & 1 & $\sim 300$ & 0 & $\begin{array}{l}\text { Simulation results without reference to real measurements, } \\
\qquad K_{1} \text { high. }\end{array}$ \\
\hline $\begin{array}{l}\text { [26], 2-bladed, teeter hub, down wind, } \\
\text { stall controlled } 11 \mathrm{~kW} \text { turbine }\end{array}$ & $\begin{array}{l}1,15 \sim \\
1,24\end{array}$ & $25 \sim 80$ & 0 & $\begin{array}{l}\text { PSD of the turbine operating in a wind-diesel autonomous } \\
\text { system is } 3 \text { times bigger than operating connected to the grid. }\end{array}$ \\
\hline $\begin{array}{c}{[27], 500 \mathrm{~kW} \text { fixed-speed, stall- }} \\
\text { controlled wind turbine } \\
\end{array}$ & 1,45 & $\sim 4,6$ & 0 & $\begin{array}{l}\text { Wind farm and turbine power output shows a } \sqrt{N} \text { ratio } \\
\text { for } \mathrm{f}>0.07 \mathrm{~Hz}\end{array}$ \\
\hline $\begin{array}{c}\text { [28], simulated PSD (not experimentally } \\
\text { measured PSD) }\end{array}$ & 1,15 & $\begin{array}{c}\sim 10^{-4} \\
\mathrm{pu}^{2} / \mathrm{Hz}\end{array}$ & 0 & At high winds, PSD decreases in a factor of 10 . \\
\hline $\begin{array}{c}\text { [29], } 8 \times 55 \mathrm{~kW} \text { ENERCON-16 turbines } \\
\text { at Cuxhaven wind farm }\end{array}$ & 0.62 & $\begin{array}{l}\sim 10^{-4,2} \\
\mathrm{pu}^{2} / \mathrm{Hz}\end{array}$ & 0 & $\begin{array}{l}\text { Wind farm and turbine fluctuations show } \sqrt{N} \text { ratio for } \\
\qquad f>0.09 \mathrm{~Hz} \text { and } N \text { ratio for } f<0.03 \mathrm{~Hz}\end{array}$ \\
\hline$[30], 4 \times 180 \mathrm{~kW}$ wind farm at Gotland & 1,25 & $\sim 64$ & 0,17 & Spectrum of active power. Stall-regulated, fixed speed. \\
\hline [30], $4 \times 180 \mathrm{~kW}$ wind farm at Gotland & $0.8 \sim 1$ & $\sim 6.4$ & 0 & Spectrum of reactive power \\
\hline [31], GE 3.6 MW, DFIG, pitch regulated & 1.025 & & 0 & $\begin{array}{c}\text { Spectrum of mechanical power at low winds } \\
\text { (not electrical power output) }\end{array}$ \\
\hline [31], GE 3.6 MW, DFIG, pitch regulated & 1,6 & & 0 & $\begin{array}{l}\text { Slow mechanical fluctuations are attenuated by constant } \\
\text { power control at high winds. }\end{array}$ \\
\hline
\end{tabular}

* The spectrum fit neither a single slope in the double-logarithmic plot nor a slope and a horizontal zone at high frequencies. The indicated value is the mean slope, but it should be considered carefully. 
The RMS value of the fluctuation of a wind farm at frequency $f$ is the square root of $\left|\vec{S}_{N}(f)\right|^{2}$ or $S_{N, f}{ }^{2}(t)$, a Gamma random variable of shape parameter $k=1$ and scale parameter $\theta=N\left|\vec{S}_{1}(f)\right|^{2}$.

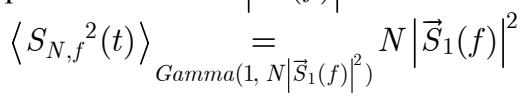

\section{CONCLUSIONS}

The wind farm oscillation amplitude due to uncorrelated sinusoidal turbine fluctuations is a Rayleigh random variable of with scale parameter $\sqrt{ } \mathrm{N}$ times the uncorrelated fluctuation of a single turbine. The instantaneous fluctuation is distributed normally with standard deviation $\sqrt{ } \mathrm{N}$ times the turbine uncorrelated fluctuation. The squared instantaneous fluctuation shows a gamma distribution with unity shape factor. The results have been compared with experimental data through PSD measured by the authors and some PSD available in the literature. The variability of $S(f)$ have been tested using spectrograms (time-varing PSD), as shown in Fig. 6.

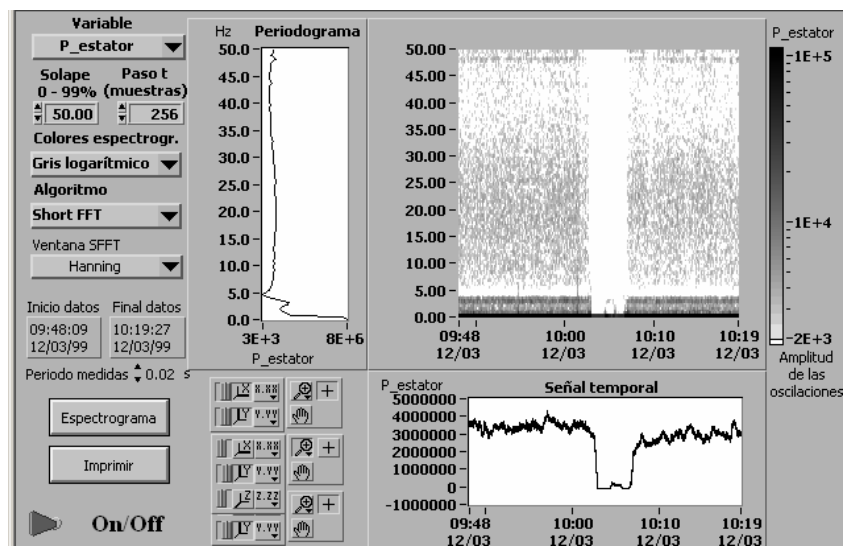

Fig. 6: Spectogram of a VRIG pitch regulated wind farm operating at low winds (including a remote commanded stop and start of the farm).

\section{ACKNOLEDGEMENTS}

The authors are grateful to Compañía Eólica Aragonesa S.A. (CEASA) and NEG-MICON (now Vestas) for their collaboration and help to install and run the measurement system.

\section{REFERENCES}

[1]Cristian Nichita, Dragos Luca, Brayima Dakyo, and Emil Ceanga, "Large Band Simulation of the Wind Speed for Real Time Wind Turbine Simulators", IEEE Transactions On Energy Conversion, Vol. 17, No. 4, Dec. 2002.

[2]T. Petru and T. Thiringer, "Modeling of Wind Turbines for Power System Studies", IEEE Trans. On Power Systems, Vol. 17, No. 4, Nov. 2002, pp. $1132-1139$

[3]J. Cidrás, A.E. Feijóo, C. Carrillo González, "Synchronization of Asynchronous Wind Turbines" IEEE Trans, on Energy Conv., Vol. 17, No 4, Nov. 2002, pp 1162-1169

[4] P. Sorensen, A. D. Hansen, P.A. Carvalho Rosas "Wind models for simulation of power fluctuations from wind farms", Journal of Wind Engineering and Ind. Aerodynamics 90 (2002), pp. 1381-1402

[5]P. Rosas, "Dynamic influences of wind power on the power system", $\mathrm{Ph} . \mathrm{D}$ Thesis, Ørsted•DTU, March 2003, ISBN: 87-91184-16-9. Avalilable at www.risoe.dk/rispubl/ VEA/veapdf/ris-r-1408.pdf

[6] W. Schlez, D. Infield, "Horizontal, two point coherence for separations greater than the measurement height", Boundary-Layer Meteor. 87 (1998), 459-480.

[7]J. Mur, M.P. Comech, "Reactive Power Injection Strategies for Wind Energy Regarding its Statistical Nature", Sixth International Workshop on LargeScale Integration of Wind Power and Transmission Networks for Offshore Wind Farm. Delft, 2006. Available at : www.joaquinmur.eu
[8]P. (Prabha) Kundur, Neal J. Balu, Mark G. Lauby, "Power System Stability and Control", McGraw-Hill, 1994.

[9]Y. Baghzouz, R. F. Burch et alter "Time-Varying Harmonics: Part IIHarmonic Summation and Propagation”, IEEE Trans. On Power Systems, Vol. 17, No. 1, January 2002, pp. 279-285.

[10] S. T. Tentzerakis and S. A. Papathanassiou, "An Investigation of the Harmonic Emissions of Wind Turbines", IEEE Trans, on Energy Conv., Vol. 22, No 1, March. 07, pp 150-158.

[11] A. Abdi, H. Hashemi, and S. Nader-Esfahani, "On the PDF of the Sum of Random Vectors", IEEE Trans. on Communications. Vol. 48, No.1, January 2000, pp 7-12.

[12] J. Mur, A.A. Bayod, S. Ortiz, R. Zapata, "Power Quality Analysis of Wind Turbines. Part II - Dynamic Analysis", ICREP 2003, Vigo. Available at: www.joaquinmur.eu

[13] T. Thiringer, T. Petru, and C. Liljegren "Power Quality Impact of a Sea Located Hybrid Wind Park", IEEE Transactions On Energy Conversion, Vol. 16, No. 2, june 2001 pp. 123-127

[14] T. Petrů, T. Thiringer "Active flicker reduction from a sea-based 2.5 MW wind park connected to a weak grid", 2000 Nordic Workshop on Power and Industrial Electronics (NORpie 2000), Aalborg, Denmark, June 13-16, 2000.

[15] T. Thiringer "Power Quality Measurements Performed on a Low-Voltage Grid Equipped with Two Wind Turbines", IEEE Trans. Energy Conversion, Vol. 11, No. 3, September 1996

[16]T. Thiringer, J.-A. Dahlberg, "Periodic Pulsations from a Three-Bladed Wind Turbine", IEEE Trans Energy Conversion, Vol. 16, No. 2, June 2001 [17] T. Thiringer, "Frequency Scanning for Power System Property Determination-Applied to a Wind Power Grid" IEEE Trans. on Power Systems, Vol. 21, No. 2, May 2006

[18] Nayeem Rahmat Ulla, "Topic 9.1: Power Quality Evaluation of a Sea Based Wind Farm", Nordic PhD course on Wind Power. Available at www.elkraft.ntnu.no/smola2005

[19]S. A. Papathanassiou and Fritz Santjer, "Power Quality Measurements in an Autonomous Island Grid with High Wind Penetration", IEEE Transactions on Power Delivery, Vol 21, No 1, Jan. 2006, pp 218 - 224

[20] C. Vilar Moreno, "Voltage fluctuation due to constant speed wind generators" Ph.D. dissertation at Carlos III University, Leganés, Spain, 2003.

[21]T. Petru "Modeling of wind turbines for Power System Studies", Ph. Disertation, Chalmers University of Technology, Goteborg, Sweden2003

[22] P. Sørensen, A. D. Hansena and P. A. Carvalho Rosas, "Wind models for simulation of power fluctuations from wind farms", Journal of Wind Engineering and Industrial Aerodynamics, Vol. 90, No. 12-15, Dec. 2002, pp. 1381-1402.

[23] P. Sørensen, A. Hansen, L. Janosi, J. Bech and B. Bak-Jensen, "Simulation of Interaction between Wind Farm and Power System", Risø National Laboratory, Roskilde, December 2001. Available at www.risoe.dk/rispubl/ VEA/veapdf/ris-r-1281.pdf

[24] A. D. Hansen, P. Sørensen, F. Blaabjerg and John Becho "Dynamic modelling of wind farm grid interaction", Wind Engineering Vol. 26, No. 4, 2002, pp. 191-208

[25] W. E. Leithead and S. Domínguez, "Coordinated Control Design for Wind Turbine Control Systems”, EWEC 2006, Athens

[26]H. Bindner, P. Nørgård, "11kW Gaia Wind Turbine Connected to a Diesel Grid”, Risø-I-nr2035(EN), Risø National Laboratory, Roskilde. Available at www.gaia-wind.com

[27] Stefan Marko, Ivan Darul'a, Stanislav Vlcek, "Development Of Wind Farm Models For Power System Studies", Journal of Electrical Engineering, VOL. 56, NO. 5-6, 2005, pp. 165-168.

[28] K. Johnsen and B. Eliasson, "SIMULINK® Implementation of Wind Farm Model for use in Power System Studies", Nordic Wind Power Conference, 1-2 March, 2004, Chalmers University Of Technology.

[29] E. Welfonder, R. Neifer and M. Spaimer, "Development And Experimental Identification Of Dynamic Models For Wind Turbines", Control Eng. Practice, Vol. 5, No. 1, pp. 63-73, 1997.

[30]J. Pierik, J. Morren, T. Engelen., S. Haan, Jan Bozelie "Development and validation of wind farm models for power system studies. Alsvik wind farm results", EWEC 2006, Athens.

[31] J. Soens, J. Driesen, R. Belmans, "Equivalent Transfer Function for a Variable-speed Wind Turbine in Power System Dynamic Simulations", International Journal of Distributed Energy Resources, Volume 1 Number 2, AprilJune, 2005; pp. 111-133. 